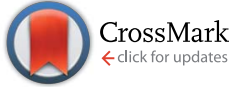

Cite this: RSC Adv., 2017, 7, 10869

Received 27th December 2016 Accepted 3rd February 2017

DOI: $10.1039 / c 6 r a 28735 b$

rsc.li/rsc-advances

\section{Construction and properties of a light-harvesting antenna system for phosphorescent materials based on oligofluorene-tethered $\mathrm{Pt}$-porphyrins $\uparrow$}

\author{
Hyeonuk Yeo, Kazuo Tanaka* and Yoshiki Chujo*
}

Tetramerous molecular assemblies composed of four oligofluorenes as a light-harvesting antenna (LHA) and a Pt-porphyrin core as a phosphorescent chromophore were designed and synthesized for obtaining efficient phosphorescent materials. The resulting molecules showed good solubility in common organic solvents and high film-formability. From the series of optical measurements, it was shown that bright phosphorescence was observed from the LHA molecules. Efficient energy transfer through the cardo structure was confirmed from the oligofluorene units to the Pt-porphyrin core. Additionally, it was shown that aggregation-caused quenching (ACQ) and oxygen-deactivation of phosphorescence can be inhibited in the film state because of steric hinderance of bulky rings on the cardo structure. Finally, film materials with oxygen-resistant solid-state phosphorescence were obtained. Our material design is feasible not only for constructing highly-emissive solid-state phosphorescent materials but also for enhancing environment resistance to emissive materials by a unique structural unit.

\section{Introduction}

Organic phosphorescent materials have attracted attention as a key substance to obtain highly-efficient organic light-emitting diodes (OLEDs). ${ }^{1}$ In particular, in order to realize low-cost fabrication processes such as inkjet printing and roll-to-roll methods, instead of vapor deposition, high solubility in commodity volatile solvents and good film-formability are required for emissive materials. ${ }^{2}$ Polymeric materials with luminescence properties are promising candidates as "inks" in these printing-based fabrication processes because of high filmformability and processability. ${ }^{3}$ Therefore, development of phosphorescent polymeric materials is a topic with high relevance. ${ }^{4}$ Polymer composites and organic-inorganic hybrids composed of phosphorescent dyes in the polymer matrices are a feasible platform to fabricate desired materials. ${ }^{5}$ By modulating types, combinations and component ratios, multi functions can be obtained based on the preprogrammed design. However, there are still difficulties to realize and maintain homogeneous dispersion states at the molecular level.

To obtain polymer-based luminescent materials including phosphorescent dyes, we employ the strategy for the usage of "element-blocks", which is defined as a minimum functional unit composed of heteroatoms, as a platform for material

Department of Polymer Chemistry, Graduate School of Engineering, Kyoto University, Katsura, Nishikyo-ku, Kyoto 615-8510, Japan. E-mail: kazuo123@chujo.synchem. kyoto-u.ac.jp; chujo@chujo.synchem.kyoto-u.ac.jp

$\dagger$ Electronic supplementary information (ESI) available. See DOI: 10.1039/c6ra28735b design. ${ }^{6}$ In particular, it has been revealed that various types of heteroatom-containing polymers showed unique optical properties. ${ }^{7}$ We focused on the cardo structure as shown in modified boron dipyrromethene (BODIPY) as a fundamental building block for assembling the functional optical units according to the preprogrammed design. ${ }^{8}$ It was demonstrated that owing to steric hinderances of the aromatic rings connected at the cardo boron, suppression of aggregation-caused quenching (ACQ), which is often observed as a non-radiation process in common organic dyes, was obtained, resulting in solid-state emission. In addition, these emissive properties were similar to those in the solution state. Thus, it was proposed that the cardo structure could be useful for obtaining bright solid-state emissive materials by suppressing intermolecular interactions in the molecular assembly. ${ }^{9}$ The photochemistry of the cardo structure can be also observed in the cardo carbon. ${ }^{10}$ The fluorescent dyestethered polycardofluorenes were prepared, and it was shown that the cardo structure can play a role in suppressing ACQ. Furthermore, bright emissive materials can be realized based on the light-harvesting antenna (LHA) ${ }^{\mathbf{1 1}}$ system. ${ }^{\mathbf{1 0}}$ Next our goal is to apply the advantages of the cardo structure for developing phosphorescent polymeric materials.

Herein, the synthesis and optical properties of the phosphorescent materials with multiple conjugated oligomers as an LHA unit are reported. The phosphorescent chromophore was modified with four oligofluorenes. The resulting molecules showed good solubility in common organic solvents and high film-formability. From the series of optical measurements, via the LHA process involving efficient light absorption and energy transferring, bright phosphorescence was observed in the 
solution state. Additionally, it was shown that aggregationcaused quenching (ACQ) and oxygen-deactivation of phosphorescence can be efficiently suppressed in the film state because of steric hinderance of bulky rings on the cardo structure. Finally, solid-state phosphorescence was observed even from the film sample at ambient temperature in the air. This study presents the guideline not only for constructing highly-emissive solid-state phosphorescent materials but also for enhancing environment resistance to emissive materials by a unique structural unit.

\section{Results and discussion}

The platinum(II) porphyrin complexes have been used as a pure red phosphorescent dye. Cao et al. reported OLED with tetraphenylporphyrin platinum(II) (PtTPP)-tethering polyfluorenes having higher device efficiencies than those with the blends with PFs and PtTPP. ${ }^{12}$ However, their system presented embarrassing transfer efficiency of the exciton derived from the heterogeneous location of PtTPP by random copolymerization. To obtain homogeneous materials containing PtTPP, the molecular assembly was designed. In the previous study with the dye-tethered polycardofluorenes, it was demonstrated that effective energy transfer can proceed through the cardo structure. ${ }^{10}$ Based on this information, the tetramerous molecules with PtTPP connected to four oligofluorenes via the cardo structure were designed (Fig. 1). The cardo structures were configured by one of the phenyl groups of PtTPP, and the PtTPP unit was surrounded by four oligofluorenes which would work as an efficient LHA because of large light-absorption and exciton-carrier abilities. Therefore, it was proposed that the excitons in the oligofluorene units could be transferred with high efficiency to the PtTPP unit, resulting in the amplified phosphorescence from PtTPP. The oligofluorene units could also work as the matrix for maintaining dispersion of PtTPP. It was also presumed that the phosphorescent properties of PtTPP could be preserved by the directly-connected cardofluorene from specific or non-specific aggregations which induce critical changes in the optical properties. Moreover, it was expected that the PtTPP units were able to be homogeneously dispersed even in the solid state, leading to solid-state phosphorescence. To

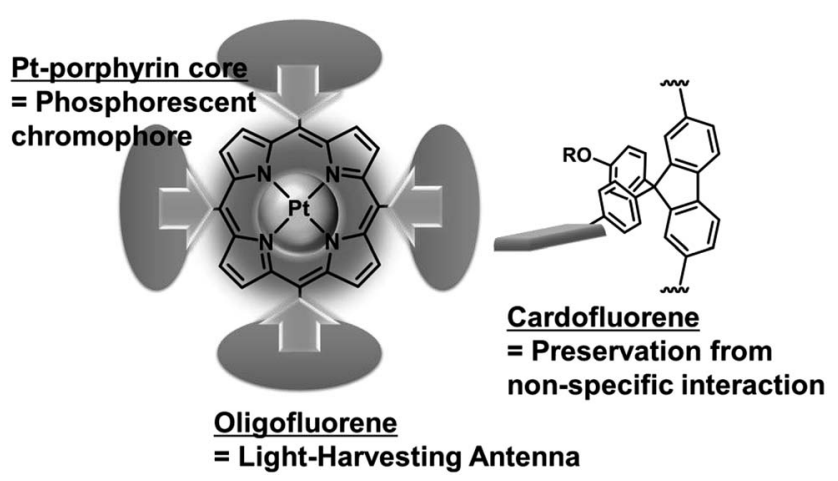

Fig. 1 Proposed mechanism of the LHA system for obtaining enhanced phosphorescence. confirm the validity of this idea, we prepared the target molecules and evaluated their optical properties.

The syntheses of the LHA molecules were performed according to Scheme 1 . The porphyrin ring was directly constructed with pyrrole and formyl dibromocardofluorene via the Rothemund condensation. ${ }^{13}$ Subsequently, by the metalation with $\mathbf{H 2 P}-\mathrm{Br}$ in the presence of $\mathrm{PtCl}_{2}$ and $\mathrm{PhCN}$, the promising $\mathrm{Pt}$-porphyrin core unit in the tetramerous molecule PtP-Br was obtained. PtPF5 and PtPF7 were obtained from the connection with the boronic acids of the dimers or the trimers of cardofluorenes via Suzuki-Miyaura coupling reactions, respectively. ${ }^{\mathbf{1 4}}$ After reprecipitation in methanol several times and drying, the products having good solubility in conventional organic solvents such as chloroform, dichloromethane and tetrahydrofuran were isolated. The characterization data were collected with ${ }^{1} \mathrm{H}$ and ${ }^{13} \mathrm{C}$ NMR spectroscopies and mass measurements. From NMR spectra, it was shown that the data for structural analyses of the products were corresponded to those of the cardofluorene monomer. In addition, the single signal peaks were observed from each compound at the expected position by the mass measurements, indicating mono-dispersed macromolecular molar masses. Thus, it was concluded that the products should possess the designed chemical structures.

The optical properties of the LHA molecules were initially investigated by UV-vis absorption in chloroform (Fig. 2a and Table 1). The measurements were executed with the samples containing $1.0 \times 10^{-6} \mathrm{M}$ of the PtTPP unit. Influence of the oligofluorene units on the electronic properties of the porphyrin center in the ground state was examined. PtTPP exhibited the strong and sharp absorption peak at $400 \mathrm{~nm}$ (Soret band) and the weak absorption peak at $510 \mathrm{~nm}$ (Q band). Correspondingly, the LHA molecules showed the strong absorption band around $400 \mathrm{~nm}$ and the weak absorption band around $510 \mathrm{~nm}$ although the absorption band in shorter wavelength region was overlapped in PtPF7 because of existence of the large absorption band with the peak around $370 \mathrm{~nm}$ attributable to the oligofluorene units. In particular, peak positions of both Soret and Q bands were hardly shifted by the introduction of the oligofluorene units. This fact means that the Pt-porphyrin core should be electronically independent to the oligofluorene units. Moreover, the increase of a molar extinction coefficient was observed by increasing the number of fluorene in the absorption bands of oligofluorenes. It was suggested that electronic conjugation should be developed not between the Pt-porphyrin core and oligofluorenes but in the oligofluorene units. The cardo structure should be responsible for the electronically isolation of each component in the ground state.

The absorption spectra of the LHA molecules were also measured with the film samples (Fig. $2 b$ and Table 2). The thin films were prepared on the quartz plate by the drop-casting method with the chloroform solutions containing the LHA molecules $\left(1.0 \mathrm{mg} \mathrm{mL}^{-1}\right)$. Surprisingly, almost same shapes of the absorption spectra to those of solutions were obtained from the films. It should be mentioned that peak broadening and red-shifting were hardly observed even in the condensed state despite Pt-porphyrin complexes commonly possess critically high aggregation ability. ${ }^{15}$ Steric distributions of oligofluorenes 


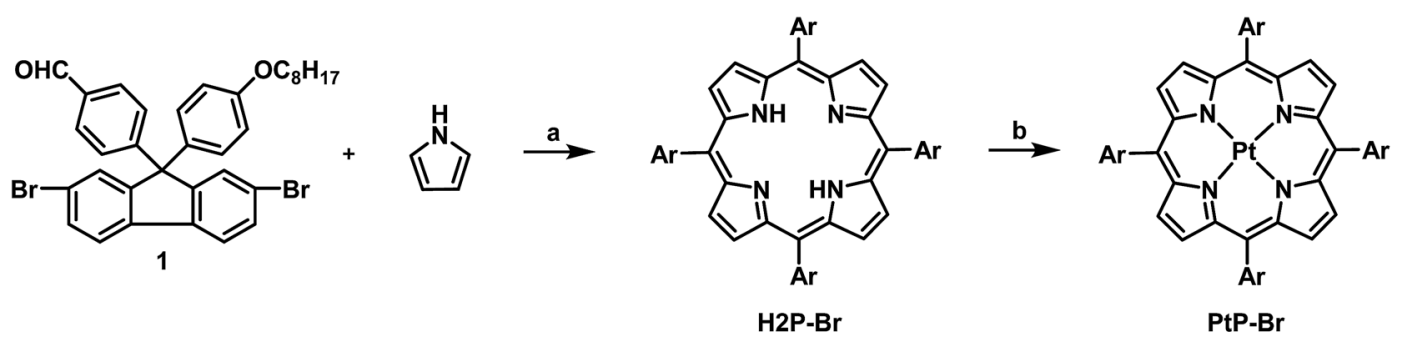

$\operatorname{Ar}=$<smiles>CCCOc1ccc(C2(c3ccc(C)cc3)c3cc(Br)ccc3-c3ccc(Br)cc32)cc1</smiles>

$\mathrm{H} 2 \mathrm{P}-\mathrm{Br}$ PtP-Br

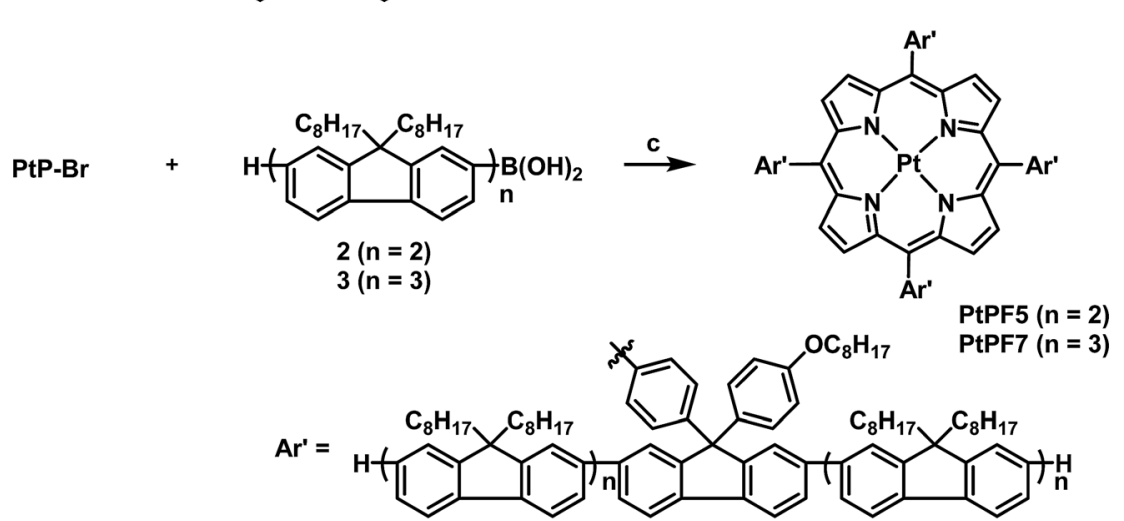

Scheme 1 Synthesis of the LHA molecules. Reagents and conditions: (a) trifluoroacetic acid in degassed $\mathrm{CH}_{2} \mathrm{Cl}_{2}, \mathrm{r} . t .$, for $12 \mathrm{~h}$ and DDQ $5 \mathrm{~h}$; (b) $\mathrm{PtCl}_{2}$ in $\mathrm{PhCN}$ refluxed for $2 \mathrm{~h}$, and $\mathrm{H} 2 \mathrm{P}-\mathrm{Br}, 195^{\circ} \mathrm{C}$, overnight; (c) $\mathrm{Pd}_{2}(\mathrm{dba})_{3}, \mathrm{~S}-\mathrm{Phos}, \mathrm{Cs}_{2} \mathrm{CO}_{3}$, toluene, $\mathrm{H}_{2} \mathrm{O}, 90^{\circ} \mathrm{C}, 2 \mathrm{~d}$.

on the cardo structures should contribute to crucially disturbing intermolecular interactions of the Pt-porphyrin core, leading to the preservation of electronic structures even in the condensed state.

The photoluminescence (PL) spectra of the LHA were measured in the chloroform solutions with the excitation light at $373 \mathrm{~nm}$ (Fig. 3a). To suppress the annihilation of phosphorescence by oxygen, samples solutions were prepared with Ar bubbling. The LHA molecules showed strong emissions in the region from $400 \mathrm{~nm}$ to $500 \mathrm{~nm}$ and weak emissions around $670 \mathrm{~nm}$. It should be emphasized that the emission intensities of the LHA molecules at $670 \mathrm{~nm}$ markedly increased. From the PtPF5 and PtPF7 solutions, the 11- and 16-times larger intensities were observed than that of PtTPP, respectively. These data are the direct evidence to show the LHA effect by the oligofluorene units. From the comparison with the spectrum from the PtTPP solution and lifetime measurements, it was proposed that the emission bands around $670 \mathrm{~nm}$ should be attributable to phosphorescence from the Pt-porphyrin cores. These data were supported by the fact that only the emission bands in the longer wavelength region were annihilated by the $\mathrm{O}_{2}$-bubbling treatment. It was confirmed that the emissions in the shorter
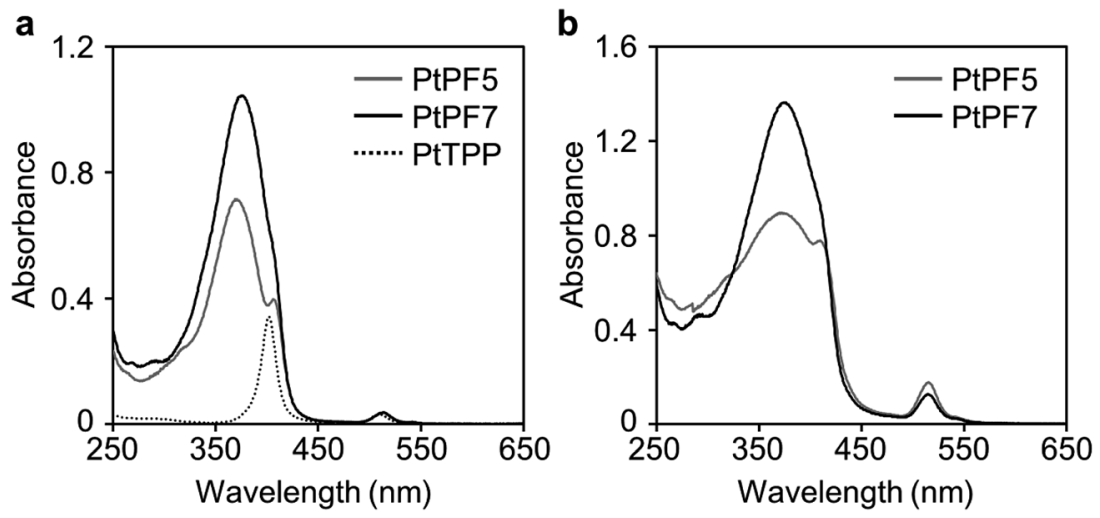

Fig. 2 UV-vis absorption spectra of the LHA molecules and PtTPP (a) in chloroform $\left(1.0 \times 10^{-6} \mathrm{M}\right)$ and (b) in the film state. 
Table 1 Photophysical properties of the LHA molecules in chloroform solutions

\begin{tabular}{llllllll}
\hline Compound & $\lambda_{\mathrm{abs}, \max }{ }^{a} / \mathrm{nm}$ & $\lambda_{\mathrm{PL}, \max }{ }^{b} / \mathrm{nm}$ & $\Phi_{\mathrm{FL}}{ }^{c}$ & $\Phi_{\mathrm{PL}}{ }^{d}$ & $E_{\mathrm{eff}, \Phi}{ }^{e}$ & $\tau^{f} / \mu \mathrm{s}$ & $\chi^{2 f}$ \\
\hline PtPF5 & 371,513 & 410,672 & 0.02 & 0.004 & 0.98 & 0.58 & 1.05 \\
PtPF7 & 375,513 & 414,671 & 0.10 & 0.004 & 0.89 & 0.52 & 1.01 \\
PtTPP & 402,510 & 663 & - & 0.002 & - & 0.46 & 1.13
\end{tabular}

${ }^{a}$ Evaluated in chloroform $\left(1.0 \times 10^{-6} \mathrm{M}\right) \cdot{ }^{b}$ Excited at $373 \mathrm{~nm}$ in chloroform $\left(1.0 \times 10^{-7} \mathrm{M}\right) \cdot{ }^{c}$ Absolute quantum yields of the emission region of oligofluorenes. ${ }^{d}$ Absolute quantum yields of the emission region of the Pt-porphyrin core without $\mathrm{O}_{2}$ degassing. ${ }^{e}$ Energy transfer efficiencies calculated by quantum yields (FL5: 0.85, FL7: 0.91 in chloroform). ${ }^{f}$ PL lifetimes at the emission wavelength at $670 \mathrm{~nm}$ in chloroform (1.0 $\times$ $\left.10^{-7} \mathrm{M}\right) .{ }^{g}$ LHA efficiencies were calculated with the comparison to intensity of PtTPP excited at $402 \mathrm{~nm}$.

Table 2 Photophysical properties of the LHA molecules in the film state

\begin{tabular}{lllllll}
\hline Compound & $\lambda_{\text {abs,max }}{ }^{a} / \mathrm{nm}$ & $\lambda_{\mathrm{PL}, \max }{ }^{b} / \mathrm{nm}$ & $\Phi_{\mathrm{FL}}{ }^{c}$ & $\Phi_{\mathrm{PL}}{ }^{d}$ & $E_{\mathrm{eff}, \Phi}{ }^{e}$ & $\tau^{f} / \mu \mathrm{S}$ \\
\hline PtPF5 & 372,515 & 665 & 0.001 & 0.024 & $>0.99$ & 11 \\
PtPF7 & 376,514 & 664 & 0.001 & 0.026 & $>0.99$ & 11
\end{tabular}

${ }^{a}$ Evaluated in the film state. ${ }^{b}$ Excited at $373 \mathrm{~nm} .{ }^{c}$ Absolute quantum yields of the emission region of oligofluorenes. ${ }^{d}$ Absolute quantum yields of the emission region of the Pt-porphyrin core. ${ }^{e}$ Energy transfer efficiencies calculated by quantum yield. ${ }^{f}$ PL lifetimes on emission wavelength at $670 \mathrm{~nm}$ in film states.

and longer wavelength regions were attributable to fluorescence of the oligofluorene units and to phosphorescence from the Ptporphyrin cores, respectively. These results represent that the tetramerous molecules can gather incident light and generate enhanced phosphorescence.

In the excitation spectra recorded at $670 \mathrm{~nm}$, it was shown that the peak shapes were corresponded to those in absorption spectra (Fig. S1 $\dagger$ ). These data indicate that energy transfer should occur in the LHA molecules. The energy transfer efficiencies, calculated by quantum yield, are listed in Table 1 . PtPF5 indicated the larger value over $97 \%$. This result means that highly-efficient energy transfers from the oligofluorene units to the Pt-porphyrin core through the cardo structure should proceed, resulting in amplification of emission intensities. PtPF7 presented relatively lower energy transfer efficiency $\left(\eta_{\mathrm{ET}}=0.89\right)$ than that of PtPF5. It is implied that intramolecular motions in the longer conjugation unit might consume excitation energy, resulting in deactivation of excited states before energy transferring. The LHA effects were also observed at $-196{ }^{\circ} \mathrm{C}$ in the 2-Me-THF solution (Fig. 3b). The excitation spectra at $-196{ }^{\circ} \mathrm{C}$ indicated that energy transfer should occur in this temperature range (Fig. S2 $\dagger$ ). Emission intensities of phosphorescence were significantly enhanced by cooling. It is likely that molecular motions should be completely frozen in this temperature range, leading to apparent dual emissions in the blue and orange emission ranges.

Finally, the PL properties of the LHA molecules as a solidstate emissive material were examined with the film samples (Fig. 4). To evaluate the effect of the connection of the oligofluorene units to the Pt-porphyrin core, the composite films containing PtTPP in oligofluorenes (5 mer: 5FL and 7 mer 7FL) were also prepared with the drop-casting method with the same ratios to the LHA molecules. From the composite films, both emissions including fluorescence from oligofluorenes and phosphorescence from PtTPP were observed. Remarkably, single phosphorescence bands were observed from the films of
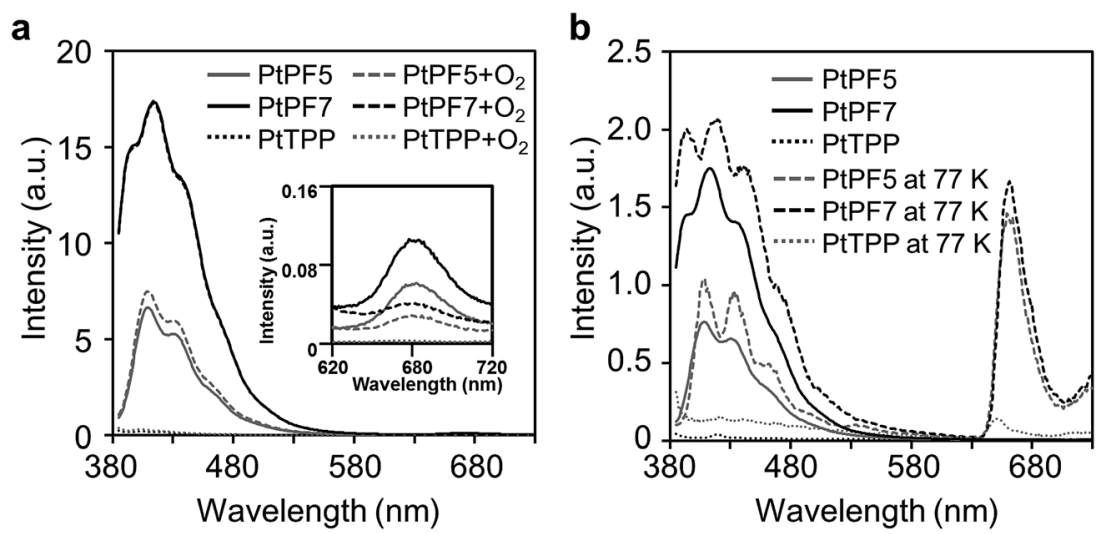

Fig. 3 PL spectra of the LHA molecules and PtTPP (excitation wavelength: $373 \mathrm{~nm}$ ) (a) in chloroform $\left(1.0 \times 10^{-7} \mathrm{M}_{1} \mathrm{Ar}^{-}\right.$or $\left.\mathrm{O}_{2}-\mathrm{bubbling}\right)$ and (b) in 2-Me-THF $\left(1.0 \times 10^{-7} \mathrm{M}\right.$, at $25^{\circ} \mathrm{C}$ or $\left.-196^{\circ} \mathrm{C}\right)$. 


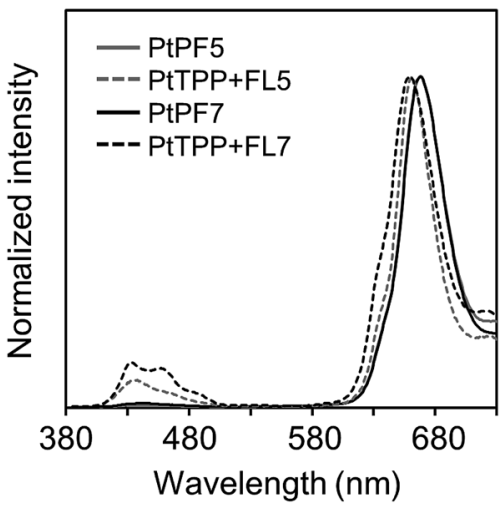

Fig. 4 Normalized PL spectra of the LHA molecules in the film state with the excitation at $373 \mathrm{~nm}$.

the LHA molecules. This result indicate that energy transferring efficiencies should be greatly enhanced in the film state. Furthermore, ACQ was effectively avoided in the Pt-porphyrin core although fluorescence was deactivated, resulting in the solid-state phosphorescence. It should be mentioned that all measurements with the film samples were performed in the air. This fact means that the phosphorescent films have $\mathrm{O}_{2}$ resistance. Furthermore, to check the $\mathrm{O}_{2}$ resistance of phosphorescence in the film, we evaluated influence of oxygen concentration on phosphorescence by soaking the film sample into water with or without deoxygenated treatment (Fig. S4†). Then, less critical changes in the spectra were observed between both samples. This result also means that the film sample has high $\mathrm{O}_{2}$ resistance. Thus, it was clearly indicated that the tetramerous structure is valid to preserve phosphorescence from the annihilation of $\mathrm{O}_{2}$. Owing to the steric distributions of the oligofluorene units, accessibility of external molecules including oxygen should be highly restricted. As a result, ACQ can be suppressed even in the condensed state. Moreover, $\mathrm{O}_{2}{ }^{-}$ resistant phosphorescence was obtained from the films. Furthermore, since electronic structures were also preserved, bright solid-state emission via the LHA system can be realized.

\section{Conclusion}

The LHA system to offer phosphorescence was constructed based on the tetramerous molecular architectures. By the modification of the Pt-porphyrin complex with two types of size-definitive oligofluorenes, emissive materials can be obtained. In summary, it was confirmed that enhanced phosphorescence can be observed via the LHA process. Moreover, solid-state phosphorescence with oxygen resistance was detected from the film samples. This manuscript presents three significant issues for the design of solid-state emissive materials: firstly, the cardo structure is the versatile platform for realizing solid-state emission. Since functional units can be distributed sterically, undesired intermolecular interactions such as stacking can be disturbed, resulting in the suppression of ACQ. This unique structural feature is favorable for receiving solid-state emission. Moreover, by regulating accessibility due to steric hinderance, environmental resistance can be improved. Secondly, electronic delocalization and conjugation are prohibited through the cardo structure. This fact means that each functional unit can show original and intrinsic properties even after the connection. In this study, both fluorescence and phosphorescence properties of the LHA molecules can be obtained independently in the solution state, resulting in the dual emissions. Thirdly, energy transferring is capable through the cardo structure. As presented here, the LHA and emissive materials can be constructed according to the preprogrammed design. Thus, it can be said that the cardo structure is versatile platforms for producing unique multi-functional optical materials.

\section{Acknowledgements}

This work was partially supported by the Noguchi Institute (for K. T.) and a Grant-in-Aid for Scientific Research on Innovative Areas "New Polymeric Materials Based on Element-Blocks (No. 2401)” (JSPS KAKENHI Grant Number JP24102013).

\section{References}

1 F. Kessler, Y. Watanabe, H. Sasabe, H. Katagiri, M. K. Nazeeruddin, M. Grätzel and J. Kido, J. Mater. Chem. C, 2013, 1, 1070-1075; C.-H. Shih, P. Rajamalli, C.-A. Wu, M.-J. Chiu, L.-K. Chu and C.-H. Cheng, J. Mater. Chem. C, 2015, 3, 1491-1496; T. Kamata, H. Sasabe, Y. Watanabe, D. Yokoyama, H. Katagiri and J. Kido, J. Mater. Chem. C, 2016, 4, 1104-1110.

2 K. Tanaka and Y. Chujo, Macromol Rapid Commun, 2012, 33, 1235-1255; R. Yoshii, H. Yamane, A. Nagai, K. Tanaka, H. Taka, H. Kita and Y. Chujo, Macromolecules, 2014, 47, 2316-2323; S. Ameen, J. Lee, H. Han, M. C. Suh and C. Lee, RSC Adv., 2016, 6, 33212-33220.

3 A. Teichler, Z. Shu, A. Wild, C. Bader, J. Nowotny, G. Kirchner, S. Harkema, J. Perelaer and U. S. Schubert, Eur. Polym. J., 2013, 49, 2186-2195; H. Zheng, Y. Zheng, N. Liu, N. Ai, Q. Wang, S. Wu, J. Zhou, D. Hu, S. Yu, S. Han, W. Xu, C. Luo, Y. Meng, Z. Jiang, Y. Chen, D. Li, F. Huang, J. Wang, J. Peng and Y. Cao, Nat. Commun., 2013, 4, 1971.

4 K. Tanaka, A. Hirose, K. Tamashima and Y. Chujo, Macromol. Rapid Commun., 2015, 36, 684-688; A. Hirose, K. Tanaka, K. Tamashima and Y. Chujo, Tetrahedron Lett., 2014, 55, 6477-6481; S. Gong, C. Yang and J. Qin, Chem. Soc. Rev., 2012, 41, 4797-4807; Y. V. Romanovskii, A. Gerhard, B. Schweitzer, U. Scherf, R. Personov and H. Bässler, Phys. Rev. Lett., 2000, 84, 1027.

5 H. Okada, K. Tanaka and Y. Chujo, Bioorg. Med. Chem., 2014, 22, 3141-3145.

6 Y. Chujo and K. Tanaka, Bull. Chem. Soc. Jpn., 2015, 88, 633643.

7 Y. Matsumura, M. Ueda, K. Fukuda, K. Fukui, I. Takase, H. Nishiyama, S. Inagi and I. Tomita, ACS Macro Lett., 2015, 4, 124-127; Y. Matsumura, K. Fukuda, S. Inagi and I. Tomita, Macromol. Rapid Commun., 2015, 36, 660-664; 
F.-B. Zhang, Y. Adachi, Y. Ooyama and J. Ohshita, Organometallics, 2016, 35, 2327-2332; J. Ohshita, M. Miyazaki, M. Nakashima, D. Tanaka, Y. Ooyama, T. Sasaki, Y. Kunugi and Y. Morihara, RSC Adv., 2015, 5, 12686-12691; M. Nakashima, T. Otsura, H. Naito and J. Ohshita, Polym. J., 2015, 47, 733-738.

8 H. Yamane, S. Ito, K. Tanaka and Y. Chujo, Polym. Chem., 2016, 7, 2799-2807; H. Yamane, K. Tanaka and Y. Chujo, Tetrahedron Lett., 2015, 56, 6786-6790.

9 H. Yeo, K. Tanaka and Y. Chujo, J. Polym. Sci., Part A: Polym. Chem., 2012, 50, 4433-4442.

10 H. Yeo, K. Tanaka and Y. Chujo, J. Polym. Sci., Part A: Polym. Chem., 2015, 53, 2026-2035; H. Yeo, K. Tanaka and Y. Chujo, Polymer, 2015, 60, 228-233; H. Yeo, K. Tanaka and Y. Chujo, Macromolecules, 2013, 46, 2599-2605; H. Yeo, K. Tanaka and Y. Chujo, Macromolecules, 2016, 49, 8899-8904.

11 R. K. Dubey, D. Inan, S. Sengupta, E. J. Sudhölter, F. C. Grozema and W. F. Jager, Chem. Sci., 2016, 7, 35173532; R. Croce and H. van Amerongen, Nat. Chem. Biol., 2014, 10, 492-501; Y. Sun, F. Guo, T. Zuo, J. Hua and G. Diao, Nat. Commun., 2016, 7, 12042; S. Jin, H. J. Son, O. K. Farha, G. P. Wiederrecht and J. T. Hupp, J. Am. Chem. Soc., 2013, 135, 955-958; M. Yamamura, S. Yazaki, M. Seki, Y. Matsui, H. Ikeda and T. Nabeshima, Org. Biomol. Chem., 2015, 13, 2574-2581; V. S. Lin,
S. G. DiMagno and M. J. Therien, Science, 1994, 264, 11051111; N. Aratani, D. Kim and A. Osuka, Acc. Chem. Res., 2009, 42, 1922-1934; Y. Sun, Z. Chen, E. Puodziukynaite, D. M. Jenkins, J. R. Reynolds and K. S. Schanze, Macromolecules, 2012, 45, 2632-2642; P. D. Frischmann, K. Mahata and F. Wurthner, Chem. Soc. Rev., 2013, 42, 1847-1870; D. Okada, T. Nakamura, D. Braam, T. D. Dao, S. Ishii, T. Nagao, A. Lorke, T. Nabeshima and Y. Yamamoto, ACS Nano, 2016, 10, 7058-7063; M. Kozaki, S. Suzuki and K. Okada, Chem. Lett., 2013, 42, 1112-1118; A. Uetomo, M. Kozaki, S. Suzuki, K. Yamanaka, O. Ito and K. Okada, J. Am. Chem. Soc., 2011, 133, 13276-13279; S. Suzuki, M. Kozaki, K. Nozaki and K. Okada, J. Photochem. Photobiol., C, 2011, 12, 269-292.

12 W. Zhuang, Y. Zhang, Q. Hou, L. Wang and Y. Cao, J. Polym. Sci., Part A: Polym. Chem., 2006, 44, 4174-4186.

13 J. S. Lindsey, I. C. Schreiman, H. C. Hsu, P. C. Kearney and A. M. Marguerettaz, J. Org. Chem., 1987, 52, 827-836.

14 D. Katsis, Y. Geng, J. Ou, S. Culligan, A. Trajkovska, S. H. Chen and L. Rothberg, Chem. Mater., 2002, 14, 13321339.

15 K. Tanaka, H. Okada, W. Ohashi, J.-H. Jeon, K. Inafuku and Y. Chujo, Bioorg. Med. Chem., 2013, 21, 2678-2681; K. Tanaka, K. Inafuku and Y. Chujo, Chem. Commun., 2010, 46, 4378-4380. 